\title{
Assessment of Learning Difficulties (LD) in Writings of Arab Learners: A Perspective
}

\author{
Mona Saleh Alanazi* \\ Department of Education, Rafha Female Campus, Northern Border University, Rafha, Kingdom of Saudi Arabia (KSA)
}

Corresponding author: Mona Saleh Alanazi, E-mail: mona70546@gmail.com

\section{ARTICLE INFO}

Article history

Received: May 25, 2017

Accepted: July 20, 2017

Published: July 31, 2017

Volume: 5 Issue: 3

Conflicts of interest: None

Funding: None

\begin{abstract}
The last four decades have observed a renewed research interest in the area of error analysis. It has been the focus of attention, and subject of debate, among scholars particularly those of second-language acquisition. Scholars in this area of study hold the unanimous view that errors are an integral and unavoidable feature of second-language acquisition. The purpose of the present paper is to analyze and classify the persistent errors committed by Saudi Arabian students at Northern Border University, Rafha while composing a variety of written texts in English. In the investigation, an effort has been made to uncover the causes and sources of various errors of usage at different linguistic levels, viz.-a-viz., grammar, morphology, syntax, lexico-semantics, spelling etc. The study aims at investigating the frequency of production of these errors of usage, expressing the findings as percentage, mean and standard deviation, across the different levels of learning (levels 1 to 4). The entire population of the study consisted of 106 English students from the first two levels under investigation, registered in the first and second semesters of the 20162017. All of the students under investigation were male and had a homogenous pre-university and university background. Upon a cursory look at the data in terms of percentage, the subjects have been found to produce the highest number of errors in the subcategory "articles", and a smaller number of errors in the subcategory 'present progressive instead of past'. In the major linguistic category 'morphological errors', the learners have been found to produce the highest percentage of errors. In another major linguistic category of errors, 'syntactic errors', the subcategory 'noun + adjective instead of adjective + noun' received the highest number of errors, whereas the subcategory 'overuse of conjunction 'and" has been found to receive the least number of errors.
\end{abstract}

Key words: Learning Difficulties, Grammatical Errors, Morphological Errors,

Syntactic Errors, Lexico-Semantic Errors, Spelling Errors

\section{INTRODUCTION}

Writing is a challenging task, even in one's first language. In the case of a foreign language, it appears to be even more complicated. As a lingua franca, English is needed in every sphere of modern society. Appropriateness in the use of language facilitates a better understanding between the sender and the receiver of the message, especially when a written mode of communication is used. Although errors are unavoidable and an integral part of learning - clear proof of the fact that learning is in progress, they can also be a major cause for misunderstanding or even communication failure. Corder (2000) argues that not only do language learners necessarily produce errors while communicating in a foreign language, these errors (if studied carefully) provide significant insights into how languages are actually learned. He is of the opinion that studying learners' errors of usage has a very effective and immediate practical application for language teachers. He maintains the view that errors provide feedback, and let the teacher know how effective his/her teaching is.

Yankson (2000) admitted that nobody learns a language without goofing, i.e. without committing silly mistakes.
According to him, goofs should not be treated as linguistic sins to be condemned and punished. He further argues that learners' errors actually facilitate the process of acquiring the second language. Olasehinde (2000) states that the process of committing errors and misuse of language by students is a direct consequence of poor teaching methodology and insufficient resources. According to him, ignorance, carelessness, and a lack of practice are the other factors responsible for the production of errors of usage. Broughton et al. (2002) claim that the teacher needs to know what rules have been broken in students' writing and speech in order to correct the errors of usage. Opara (2001) labeled errors of usage inaccuracies which occur as a result of language misuse. He argues that it is very difficult to do away with errors completely. According to him, it is linguistic interference which is mainly responsible for language misuse and the generation of other related errors of usage. Orisawayi (1984) asserts that errors are mistakes but form part of the learning of a language. He added that learners misuse language due to their carelessness. He further stresses that "errors have a peculiar sneaky behavior, such that no matter the number of times a piece of 
work is read through, one cannot rule out the possibility of some mistakes stealthily surviving the revision and proofreading sessions".

The concept of Error Analysis (EA), a subarea of applied linguistics, is central to the study of second language learning. It is a technique of measuring progress in second/foreign language learning by analyzing errors committed by an individual learner or a group of learners in the course of learning their target language (TL). The technique of Error Analysis (EA) in Second Language Acquisition was established in the 1960s by Stephen Pit Corder and his colleagues. The shortcomings of Contrastive Analysis (CA), an approach influenced by behaviorism, led to the widespread acceptance of the technique of error analysis influenced by mentalist thought. When contrastive analysis began to lose ground, error analysis began to take hold and gain momentum. This resulted in a shift in emphasis from the grammatical structure of a language to the underlying rules governing the language.

According to Richards (1992), error analysis presupposes that some learning has taken place in the form of an input. He also cites French (1989) where he states that "errors are oddities that are not evidence of carelessness or of unwillingness, but of growing pains and a desire to learn - not punishable offences, because they are accidents." Candling (2001) considers error analysis as the "monitoring and analysis of learner's language." He refers to an error as a deviation. Dulay and Burt (1974) hold the view that errors are "instances of deviation from the norms."

\section{Research Questions}

The study aims to answer the following research questions:

1. Is there any variation between the performance of students' learning and their generation of usage errors across all the levels?

2. In which linguistic category do the learners commit the maximum number of errors?

3. Are the errors committed by the students the same or different across all the linguistic categories?

\section{REVIEW OF LITERATURE}

By the middle of the $20^{\text {th }}$ century, when Behaviorism and Structuralism were very popular, Contrastive Analysis (CA) was widely employed in second language teaching. CA was treated as a remedy for language teaching related problems. Since the approach was popular, many contrastive studies (generally those pedagogical in nature) were conducted to analyze learners' errors. Brown (2000, p. 208) admits that "the principal barrier to the second language system is the interference of the first language system with the second language system." Thus, in a way, first language interference has been found to have a large impact on second language learning. Lado (1957, p. 2) claimed that "the student who comes in contact with a foreign language will find some features of it quite easy and others extremely difficult." In comparison to the native language, similar elements will be simple for learners, and different elements will be difficult.
Stockwell, Bowen and Martin (1965) asserted that the main source for predicting the difficulties is the interference between native language and target language.

Stephen Pit Corder, generally regarded as the father of error analysis, is credited with reviving interest in the area of error analysis by providing pioneering pieces of research work in this area. It was with the publication of his article "The significance of Learner Errors" (1967) that modern error analysis was launched. Corder came forward with an entirely different point of view and argued that errors used to be "flaws" that needed to be eradicated. Corder (1967) noted, "a learner's errors are significant in that they provide to the researcher evidence of how language is learned or acquired, what strategies or producers the learner is employing in the discovery of the language." He further stated that errors are "important in and of themselves". For learners themselves, errors are 'indispensable,' thus the committing error is considered as a tool learners' use in learning. According to Gass and Selinker (1994), errors are "red flags" that reflect evidence of the learners' knowledge of the second language. Richards (1974), Dulay and Burt (1974) and Taylor (1975) argue that errors contain valuable information about strategies that people employ to acquire a language. Richards and Sampson (1974, p. 5) state that "at the level of pragmatic classroom experience, error analysis will continue to provide one means by which the teacher assesses learning and teaching and determines priorities for future effort." Michaelides (1990, p. 30) concludes in his study that the systematic analysis of students' errors can be of great value to all those concerned, i.e. the teacher, the student, and the researcher. It offers the teacher a clear and reliable picture of his students' knowledge of their target language. Willcot (1972, p. 73) carried out an error analysis study to explore some of the problems that native speakers of Arabic encounter with the syntax of written English. Willcot found that definiteness errors were the most frequent among his subjects. Scott and Tucker (1974, p. 186) studied the errors committed by 22 Arab students enrolled in their first semester of a low-intermediate intensive English course at the American University of Beirut. The results of the study revealed that verbs, prepositions, articles and relative clauses were the areas where the students committed errors most frequently. In his study of error analysis, Abbot (1980) examined the errors made by a group of his Arab EFL students. Results of his study show that $57 \%$ of the errors in the area of restrictive relative clauses were erroneous. The results of a similar kind of survey conducted by Kharma (1981) revealed that Arab EFL students commit errors in the use of English definite articles most frequently.

According to El-Sayed (1982) the subjects of his study were found to generate an enormous amount of errors in the use of different syntactic categories such as nouns, pronouns, verbs, articles, prepositions and adjectives. Al-Johani (1982) promoted a different point of view. According to him, certain shared characteristics between the native and target languages of subjects of the study facilitate the use of definite articles without presenting the test subjects with any difficulties. A very important survey in the area of error analysis of Arab EFL students was conducted by Abu-Jarad (1983). Jarad examined Palestinian EFL students, and noticed that tense shift 
was a major problem among them. Among the other categories, verb formation and copula redundancy were found to be prone to more errors and in need of teachers' immediate attention. In one more study related to error analysis, grammatical and lexical errors in the nominal groups were studied by Radwan (1988). The results of his study led him to conclude that the students under investigation generated errors in the use of articles with the greatest frequency, followed by errors in the use of relative classes, genitives, numbers, word classes, etc. The results of a similar kind of study carried out by Belhaaj (1997) revealed the grammatical errors committed by the subjects (in order of diminishing frequency of occurrence) were verb formation, relative clauses, adjectives, prepositions, nouns, and articles among others.

\section{Sources of Errors}

According to Alyewumi et al. (2004) the major sources of errors of usage are L1 interference, idiosyncrasies, inappropriate learning, and incorrect application of rules. French (1989) admits the inadequate learning and subsequent incorrect application of rules would induce errors. Richards (2000) considers errors as a direct outcome of interference between two language systems by means of social, psychological and linguistic interaction.

Allen and Corder (1981, p. 130) identified three sources of errors:

i) Language transfer

ii) Overgeneralization or analogy

iii) Methods or materials used in the teaching (teaching-induced error)

Richards and Sampson (1974, pp. 3-18) mention seven sources of errors:

i) Language transfer

ii) Intra-lingual interference

iii) Sociolinguistic situation

iv) Modality

v) Age

vi) Successions of approximative systems

vii) Universal hierarchy of difficulty

James $(1998$, p.178) reported three main sources of errors:

i) Interlingual

ii) Intralingual

iii) Induced errors

\section{Identification and Categorization of Errors}

It is essential to differentiate between "errors", which are systematic, and "mistakes", which are not. Errors are likely to be produced repeatedly and are not identified by the learner. Therefore, only a researcher or teacher would be able to identify them. Mistakes, on the other hand, follow a self-correction ability criterion, i.e. they are self-corrected when attention is called to them (Corder, 1967, 1971; James, 1998). Thus, it can be reasonably argued that mistakes are not the outcome of inefficiency or incompetence. Although the learners possess the knowledge of the correct use of the language, mistakes are just lapses and are generally regarded as a slip of the tongue or pen. Errors are committed because of the ignorance of the learners, and due to their incomplete, inappropriate and inadequate knowledge of the language. They do not know what is correct and appropriate. According to basic typology, errors can be classified as: omissive, additive, substitutive, or related to word order. Errors can be classified as overt (errors being obvious, even out of context) and covert (errors which are evident only in context). They can also be classified according to the level of language at which they occur as: phonological errors, morphological errors, lexical/ vocabulary errors, syntactic/grammatical errors, and so on.

The following categories and subcategories have been suggested for error analysis (Corder, 1974; James, 1998; Richards, 1974; Richards and Sampson, 1974; Selinker, 1972): Grammatical (prepositions, articles, reported speech, singular/plural, adjectives, relative clauses, irregular verbs, tenses and possessive case); syntactic (coordination, sentence structure, nouns, pronouns, and word order); lexical (word choice); and semantic and substance (mechanics, punctuation, and capitalization, and spellings), among others.

\section{METHODS}

\section{Sample an Sampling Technique}

With a view to examining the subjects of his study, the researcher managed to prepare and conduct several written tasks (of 250 words) both at the beginning and at the end of both semesters of the 2016-2017 academic year. In addition, the researcher recorded the errors committed by the students chosen as subjects for his study in different writing assignments, quizzes, mid-term exams and final examinations conducted during and at the end of the two semesters of the said academic year. The purpose of doing all this was to identify and categorize the errors committed.

\section{Instrument}

The entire population of the study consisted of 106 English students from the first two levels under investigation, registered in the first and second semesters of the 2016-2017 (Table 1). All of the students were male and had a homogenous pre-university and university background. All had more or less the same type of educational level before joining Northern Border University. In order to have a clear view of the students' performance in the five major problematic areas, vis-à-vis grammatical categories, morphological categories, syntactic categories, lexico-semantic categories, and spelling categories tested across the first four levels, the researcher compared the mean scores of the errors committed by students after analyzing the written tasks. All the aforementioned categories of the problematic areas were further categorized into their sub-categories shown in Tables 2.

\section{RESULTS AND ANALYSIS}

\section{Distributional Overview of Errors}

Table 2 represents an overview of errors committed by students under investigation in various problematic areas; such 
Table 1. Number of students who participated at each level

\begin{tabular}{lc}
\hline Level & Samples \\
\hline Level 1 & 29 \\
Level 2 & 28 \\
Level 3 & 27 \\
Level 4 & 22 \\
Total & 106 \\
\hline
\end{tabular}

as, grammar, morphology, syntax, lexico-semantics, and spelling respectively (which were further divided into $31 \mathrm{sub}-$ categories) across the four levels of learners being studied.

\section{Data Elaboration in Percentage Along with Error Samples}

To arrive at the desired results and correct conclusion, i.e. to test the variations in students' performance in their written English texts across all the four academic levels, the inves-

Table 2. Frequency of students' errors in all categories

\begin{tabular}{|c|c|c|c|c|c|}
\hline \multicolumn{6}{|c|}{ Grammatical errors } \\
\hline No. & Errors & Level 1 & Level 2 & Level 3 & Level 4 \\
\hline 1 & Present instead of past & 09 & 05 & 07 & 05 \\
\hline 2 & Simple past instead of present progressive & 10 & 08 & 07 & 05 \\
\hline 3 & Simple past instead of simple present & 12 & 10 & 08 & 03 \\
\hline 4 & Present progressive instead of past & 08 & 08 & 05 & 04 \\
\hline 5 & Prepositions & 58 & 69 & 37 & 53 \\
\hline 6 & Article & 77 & 48 & 53 & 47 \\
\hline 7 & Verb "be" & 22 & 21 & 22 & 15 \\
\hline 8 & Conjugation & 16 & 14 & 15 & 12 \\
\hline 9 & Auxiliary/modal "do" & 12 & 07 & 07 & 08 \\
\hline \multicolumn{6}{|c|}{ Morphological errors } \\
\hline 1 & Omission of plural "s" & 15 & 14 & 05 & 06 \\
\hline 2 & Overuse of plural "s" & 06 & 06 & 05 & 07 \\
\hline 3 & Misuse of plural "s" & 05 & 03 & 06 & 04 \\
\hline 4 & Omission of "-ing" ending in present progressive & 05 & 02 & 05 & 03 \\
\hline 5 & Possessive case formation & 15 & 11 & 10 & 08 \\
\hline 6 & Use of past tense marker "-ed" & 07 & 07 & 06 & 03 \\
\hline \multicolumn{6}{|c|}{ Syntactic errors } \\
\hline 1 & $\begin{array}{l}\text { Noun+Adjective instead of Adjective+Noun } \\
\text { ( word order) }\end{array}$ & 10 & 12 & 10 & 07 \\
\hline 2 & Run-on sentences & 08 & 05 & 08 & 12 \\
\hline 3 & Overuse of conjunction "and" & 04 & 04 & 04 & 05 \\
\hline 4 & Omission of noun after adjective & 05 & 08 & 05 & 04 \\
\hline \multicolumn{6}{|c|}{ Lexico-semantic errors } \\
\hline 1 & Misinterpretation of concepts & 16 & 14 & 12 & 12 \\
\hline 2 & Use of noun instead of verb & 12 & 08 & 07 & 07 \\
\hline 3 & Use of verb instead on noun & 10 & 07 & 08 & 07 \\
\hline 4 & Incorrect use of verb & 15 & 07 & 07 & 04 \\
\hline 5 & Incorrect use of lexemes & 24 & 10 & 07 & 06 \\
\hline \multicolumn{6}{|c|}{ Spelling errors } \\
\hline 1 & Dropping of "e" in the final position & 25 & 01 & 08 & 06 \\
\hline 2 & Replacement of "p" by "b" & 22 & 13 & 10 & 08 \\
\hline 3 & Pronunciation-based spellings & 30 & 32 & 28 & 12 \\
\hline 4 & Replacement of "i" by "e" and vice versa & 12 & 10 & 10 & 07 \\
\hline 5 & Replacement of "c" by "s" & 16 & 04 & 08 & 08 \\
\hline 6 & Dropping of " $\mathrm{k}$ " in the initial position & 08 & 06 & 05 & 08 \\
\hline 7 & Dropping of " $r$ " in the final position & 14 & 11 & 07 & 06 \\
\hline
\end{tabular}


Table 3. Descriptive statistics results of students' errors in all categories

\begin{tabular}{|c|c|c|c|c|}
\hline \multicolumn{5}{|c|}{ Grammatical errors } \\
\hline No. & Grammatical errors & Mean & Standard deviation & Percent \\
\hline 1 & Present instead of past & 6.5 & 1.65 & 3.57 \\
\hline 2 & Simple past instead of present progressive & 7.5 & 1.80 & 4.12 \\
\hline 3 & Simple past instead of simple present & 8.25 & 3.34 & 4.53 \\
\hline 4 & Present progressive instead of past & 6.25 & 1.78 & 3.43 \\
\hline 5 & Preposition & 54.25 & 11.51 & 29.84 \\
\hline 6 & Article & 56.25 & 7.43 & 30.94 \\
\hline 7 & Verb "be" & 20.01 & 2.91 & 11.00 \\
\hline 8 & Conjugation & 14.25 & 1.47 & 7.84 \\
\hline 9 & Auxiliary/Modal “do" & 8.5 & 2.06 & 4.67 \\
\hline \multicolumn{5}{|c|}{ Morphological errors } \\
\hline 1 & Omission of plural marker "-s" & 10.0 & 4.52 & 24.39 \\
\hline 2 & Overuse of plural "s" & 06 & 0.70 & 14.63 \\
\hline 3 & Incorrect use of plural "-s" & 4.5 & 1.11 & 10.97 \\
\hline 4 & Omission of "-ing" ending in present progressive & 3.75 & 1.29 & 9.14 \\
\hline 5 & Possessive case formation & 11 & 2.54 & 26.82 \\
\hline 6 & Incorrect use of past tense marker "-ed" & 5.75 & 1.63 & 14.02 \\
\hline \multicolumn{5}{|c|}{ Syntactic errors } \\
\hline 1 & Noun+Adjective instead of Adjective+Noun (word order) & 9.75 & 1.78 & 35.13 \\
\hline 2 & Run-on sentences & 8.25 & 2.48 & 29.72 \\
\hline 3 & Overuse of conjunction "and" & 4.25 & 0.80 & 15.31 \\
\hline 4 & Omission of noun after adjective & 5.5 & 1.5 & 19.81 \\
\hline \multicolumn{5}{|c|}{ Lexico-semantic errors } \\
\hline 1 & Misinterpretation of concepts & 13.5 & 1.65 & 25 \\
\hline 2 & Use of noun instead of verb & 9.5 & 2.06 & 17 \\
\hline 3 & Use of verb instead of noun & 8.5 & 1.22 & 15.4 \\
\hline 4 & Incorrect use of verb & 8.25 & 4.08 & 16.5 \\
\hline 5 & Incorrect use of lexemes & 11.75 & 7.22 & 23.5 \\
\hline \multicolumn{5}{|c|}{ Spelling errors } \\
\hline 1 & Dropping of "e" in the final position & 10 & 9.02 & 14.94 \\
\hline 2 & Replacement of "p" by "b" & 13.25 & 5.35 & 15.85 \\
\hline 3 & Pronunciation-based spellings & 25.5 & 7.92 & 30.44 \\
\hline 4 & Replacement of "i" by "e" and vice versa & 9.75 & 1.78 & 11.64 \\
\hline 5 & Replacement of "c" by “s" & 9 & 4.35 & 10.74 \\
\hline 6 & Dropping of " $\mathrm{k}$ " in the initial position & 6.75 & 1.29 & 8.05 \\
\hline 7 & Dropping of " $r$ " in the final position & 9.5 & 3.20 & 11.34 \\
\hline
\end{tabular}

tigator has calculated and compared the mean scores of the students' performance in 5 major problematic areas, vis-àvis grammar, morphology, syntax, lexico-semantics and spelling, which were further divided into 31 corresponding subcategories. Table 3 represents an overview of the mean score of students' performance in all linguistic categories across the four academic levels under investigation.

\section{Grammatical errors}

The mean scores in Table 3 show differences in students' grammatical errors tested across all four levels under inves- tigation (levels 1-4). The table shows that out of 9 grammatical subcategories, the grammatical subcategory 'articles' received the maximum number of errors, which accounts for about $30.94 \%$ of all errors committed by the learners while using different grammatical items during the course of composing different English texts. Second to it is the grammatical subcategory "preposition", which received $29.84 \%$ of the total number of errors committed by the same group of students under investigation. The grammatical subcategory 'The use of present progressive instead of past tense' received the least number of errors, accounting for only about $3.43 \%$ of the total number of errors committed by these 
learners in all 9 grammatical subcategories. From the above table it can be deduced that the students did not show any remarkable variation in committing errors while using other grammatical subcategories.

Examples:

(i) I want to be ___ doctor in this university. (omission of indefinite article ' $a$ ')

(ii) I eat my lunch in the home. (overuse of definite article 'the')

(iii) My friends Abdullah and Hassan have a same aim. (addition of indefinite article ' $a$ ')

(iv) _ the end I spoke about my aim in life. (mission of preposition in)

(v) I will to be happy if my aim is achieved. (overuse of preposition 'to')

(vi) He felt happy from this news. (use of 'from' instead of 'with')

The grammatical sub-category 'present progressive instead of past' received the lowest percentage of errors among all the sub-grammatical categories under investigation. Some examples of these errors are:

i) He is going to hospital and saw his father. (present progressive instead of simple past)

ii) $\mathrm{He}$ is finishing his homework when his father came. (present progressive instead of simple past)

Other examples of such types of errors with an average occurrence committed by the students in other grammatical categories under investigation are as follows:

i) The sky was clear and there are many stars. (present instead of past)

ii) Ahmad is now prepared for his master's course in the USA. (simple past instead of present progressive)

iii) If you worked hard, you can get good grades. (simple past instead of simple present)

iv) The teaching job __ very important in every country. (omission of verb 'be/is)

v) I was a dream to become a doctor. (incorrect use of verb 'be'; 'was' instead of 'had')

vi) I was studied hard for my exams. (overuse of verb 'be'/'was')

vii) My father go to Makkah every month. (Incorrect use of conjugation/subject-verb agreement)

viii) In my last vacation I went to Makkah and Jeddah because they are a very good places.

(incorrect use of conjugation/subject-verb agreement)

ix) __ you know how to drive? (omission of auxiliary 'do')

x) I _ not know who he is. (omission of auxiliary 'do')

\section{Morphological errors}

Table 3 shows that there are also differences in students' performance in certain morphological subcategories. The morphological subcategory 'possessive case formation' received the greatest number of errors by the students irrespective of their education level. The number of errors committed by the students accounts for about $26.82 \%$ of all six morphological subcategories of errors. Second to this was the morphological subcategory 'omission of plural marker -s', which re- ceived a percentage of as much as $24.39 \%$ of the total errors. Moreover, the morphological subcategory 'omission of "-ing" ending in present progressive tense' received the least number of errors, calculated at $9.14 \%$ of errors committed by the learners under investigation. The errors committed by the students in other morphological subcategories are presented in Table 3 percentagewise.

Following are the examples showing errors committed by the students in their L2 morphological categories.

i) That was the best vacation because we visited many place. (omission of plural "-s")

ii) There was very nice buildings and shops. (incorrect use of plural "-s")

iii) Some of the people asks me why I do this much hard work. (incorrect use of plural "-s")

iv) It took me a lot of time in finish my homework. (omission of "-ing" in past progressive)

v) My grandfather house is in a very small village. (incorrect possessive case formation)

vi) I thinked about the consequences and decided to meet him. (incorrect use of past tense marker "-ed")

vii) I catched a taxi and got there on time. (incorrect use of past tense marker "-ed")

viii) I weared new clothes in the morning and went to pray. (incorrect use of past tense marker -ed)

\section{Syntactic error}

From the mean scores of students' performance in all syntactic categories tested across all levels under investigation presented in Table 3, it can be reasonably inferred that the syntactic subcategory "word order" (noun + adjective instead of adjective + noun) received the highest number of errors. This percentage accounts for about $35.13 \%$ of errors committed by students in all syntactic subcategories. Second to this is the syntactic subcategory labeled 'run-on sentences', where the learners produced a relatively large number of errors of usage, with a percentage of about $29.72 \%$. Among all the syntactic subcategories, "overuse of conjunction "and", shows the lowest number of errors, calculated at $15.31 \%$. The percentage of errors committed by the learners in other syntactic subcategories under investigation is shown in Table 3.

Some examples of errors of these types are as follows:

i) In Rafha we went to gardens beautiful. (Noun + Adjective instead of Adjective + Noun)

ii) Different persons have different aims, and any one of them they should to achieve his aim in short time. (incorrect sentence construction/run-on sentence)

iii) I will work hard in exams and I will get more practice and in university to be good a teacher in future god will. (incorrect sentence construction/run-on sentence)

iv) We went a garden and we went to a lot of restaurants and we went to city center and it has a big beautiful shopping center and after that we went to my village. (overuse of conjunction "and")

v) We saw a big and beautiful in Jeddah (omission of noun after adjective)

vi) It is a great job and an honest (omission of noun after adjective) 


\section{Lexico-semantic errors}

The results presented in Table 3 reveal that among all 5 lexico-semantic subcategories under investigation, it is the lexico-semantic subcategory 'misinterpretation of concepts' in which the students committed the highest number of errors, accounting for about $25 \%$ of errors committed in all of the 5 lexico-semantic subcategories. Another lexico-semantic subcategory, labeled 'incorrect use of lexemes', received the next highest number of errors, with a percentage of $23.5 \%$. However, the lexico-semantic subcategory 'use of verb instead of noun' received the lowest percentage of errors $(15.4 \%)$ in the writing tasks of the students.

Following examples show these types of errors:

i) To achieve my goal I have to pick a particular area and be a part of it. (misinterpretation of concepts)

ii) I want to tell my advice to my friends. (misinterpretation)

iii) After this incident all his advices came to my brain one by one. (misinterpretation)

iv) A number of doctors are relaxing their job in this university. (misinterpretation)

v) Until I work hard I cannot success in learning English. (Noun instead of verb)

vi) The teach job is very important in every country. (Verb instead of Noun)

vii) By this job you will learn a lot of students. (incorrect use of verb)

viii) I have been living here from my children (incorrect use of lexeme)

\section{SPELLING ERRORS}

The mean scores from Table 3 show that there are variations in students' performance in all spelling subcategories. Among these subcategories the subcategory 'replacement of ' $p$ ' by ' $b$ " has emerged as being preeminent in terms of receiving errors. The number of errors found in this subcategory accounts for about $30.44 \%$ of all seven subcategories of spelling errors. Errors committed by the students in other subcategories of 'spelling errors' category are tabulated percentagewise in Table 3. Following are examples showing these types of errors of usage:

i) These $\rightarrow$ Thes (dropping of '-e' in the word-final position)

ii) Before $\rightarrow$ Befor (dropping of '-e' in the word-final position)

iii) Therefore $\rightarrow$ Therefor (dropping of '-e' in the word-final position)

iv) Two $\rightarrow$ Tow (L1/Mother tongue pull)

v) Brother $\rightarrow$ Brather (replacement of 'o' by 'a' (L1/Mother tongue pull based error)

vi) Mother $\rightarrow$ Mather (replacement of 'o' by 'a' (L1/Mother tongue pull based error)

vii) Job $\rightarrow$ jop (replacement of 'b' by 'p' (L1/Mother tongue pull based error)

viii) Patrol $\rightarrow$ batrol (replacement of 'p' by 'b' (L1/Mother tongue pull based error) ix) Pepsi $\rightarrow$ bebsi (replacement of 'p' by 'b' (L1/Mother tongue influence based error)

$\mathrm{x}$ ) Receive $\rightarrow$ recieve (replacement of 'e' by 'i' (L1/Mother tongue influence based error)

xi) Achieve $\rightarrow$ acheive (replacement of 'e' by 'i' (L1/Mother tongue influence based error)

xii) Society $\rightarrow$ Sosiety (replacement of 'c' by 's' (L1/Mother tongue influence based error)

xiii) Know $\rightarrow$ now (dropping of ' $k$ ' in the beginning of some words of English origin)

xiv) Knee $\rightarrow$ nee (dropping of ' $k$ ' in the word-initial position of some words of English origin.

$\mathrm{xv}$ ) Father $\rightarrow$ Fathe (dropping of ' $r$ ' in the word-final position)

\section{DISCUSSION}

Out of all the grammatical subcategories tabulated above, the students were found to commit more errors in the grammatical subcategories 'article' and 'preposition'. The enormous production of errors in the use of articles by Arab learners while writing their English texts may be attributed to the fact that English has definite and indefinite articles, each with a specific pattern of usage. On the contrary, Arabic only has a definite article, with a different pattern of usage from English. Similarly, most of the students were observed to omit, add incorrectly or misuse 'prepositions' in their writing tasks. Prepositions in English, similar to other languages, express the relationship between two entities and perform different functions from those in Arabic. Therefore, at times it becomes very difficult for EFL learners with an Arabic mother tongue background to use these prepositions correctly. Thus, the learners frequently omitted, added or overused these prepositions while composing their written texts in English.

The grammatical subcategory 'present progressive instead of simple past' received the lowest percentage of errors among the grammatical categories under investigation. This could be due to the fact that the learners do not make frequent use of tenses in their writing tasks. Another reason for the low percentage of errors in this particular grammatical category is that the students must have learned certain rules about the usage of tenses. A possible reason for these errors may be the lack of their exact equivalents in the learners' L1 (mother tongue). As a result the learners tend to translate literally from their native language and use 'present progressive instead of simple past'.

The different processes involved in forming words in the students' L1 and L2 led them to commit a considerable number of errors in the formation of certain morphological categories of their L2. In this situation, where the basic rules pertaining to word formation and morphological processes vary considerably, the learners are likely to produce errors while composing certain written texts in their L2. In the present investigation, the students were found to apply the basic rules of their L1 when dealing with different categories of words in their L2, which has gave rise to the production of a huge number of errors in their L2 morphological system. Moreover, their inadequate knowledge and insufficient 
competence in building morphological structures in their L2 resulted in the production of an enormous stock of errors of usage in their L2 morphological system.

Since the syntactic patterns of the subjects' L1 and L2 differ so dramatically, certain syntactic categories like 'word order' and 'use of conjunctions' have a different pattern of usage from what the subjects under investigation had prior exposure to. This variation in the students' L1 and L2 resulted in the prodigious production of errors in the learners' use of L2 syntax in the form of 'omission of noun after adjective' and 'run-on-sentences'. There is no denying the fact that constructing grammatically correct and acceptable sentences in learners' L2 requires adequate knowledge of the L2 structures. Therefore, the subjects' L1 influence and insufficient knowledge of the L2 syntax might be considered another strong reason for the extensive production of errors in the L2 syntax.

On account of insufficient knowledge of, and little control over, the L2 lexicon, the students were observed to translate a considerable number of concepts from their L1 equivalents literally. Because of this inter-lingual (negative L1) transfer, the subjects under investigation were observed to fail in making an appropriate choice of lexemes, and in assigning appropriate and acceptable meaning to a number of L2 concepts. This negative L1 transfer and literal translation of the L2 lexicon and other concepts led these students to misinterpret a sizable portion of the stock of $\mathrm{L} 2$ concepts, and assign incorrect meaning and connotations to most of these concepts and lexical items.

It is a well-known fact that learners' limited knowledge of the L2 vocabulary and the L1 influence hinder them in producing, pronouncing and therefore spelling the words accurately in their L2. Limited access and exposure to the L2 vocabulary stock and strong L1 influence are the two main factors responsible for the highest production of spelling errors in the learners' written tasks. The students' L1 influence is very clearly reflected in almost all the subcategories of the spelling error list.

\section{CONCLUSION}

Error analysis has emerged as a flourishing area in applied linguistics. Production of errors during the course of second language learning has unanimously been accepted as an unavoidable, even fruitful, process by various scholars of applied linguistics. The findings of this study reveal a clear picture of errors committed by Saudi Arabian EFL learners. These learners were found to produce the highest number of errors in the subcategory 'articles' of the major linguistic category of errors 'grammatical errors', and a smaller number of errors in the subcategory 'present progressive instead of past'. In the major linguistic category 'morphological errors'. The learners produced the highest percentage of errors in the morphological subcategory 'possessive case formation' and a smaller number of errors in the morphological subcategory 'incorrect use of plural '-s'. In another major linguistic category of errors, 'syntactic errors', the subcategory 'noun + adjective instead of adjective + noun' received the highest number of errors, whereas the subcategory 'over- use of conjunction "and" has been found to receive the least number of errors. Similarly, the subcategories 'misinterpretation of concepts' and 'use of verb instead of noun' in the major linguistic category of errors 'lexico-semantic errors' received both the highest and the lowest percentage of errors respectively. In the same way the subjects of the study produced the highest percentage of errors in the subcategory 'pronunciation-based errors' and the lowest number of errors in the subcategory 'dropping of ' $\mathrm{k}$ ' in the initial position' in the major category of errors 'spelling errors'.

Insufficient knowledge of the target language structures, limited access and exposure to the target language lexicon, lack of motivation in learners, negative L1 transfer, overgeneralization or analogy of target language material, and lack of target language environment may be some of the major causes for the production of errors of usage among Arab EFL learners. The results of this study can provide a useful source of information for English language teachers and material developers who need to make informed decisions in designing effective learning-teaching materials for these learners.

Although the study presents a comprehensive account of errors committed by Arab EFL learners, it is limited in scope in the sense that no remedial measures for the treatment of these errors have been suggested.

\section{REFERENCES}

Abbot, G. (1980). Towards a more Rigorous Error Analysis. International Review of Applied Linguistics, 18, 121-134.

Abu-Jarad, H. A. (1983). A Contrastive and Error Analysis of Tense in the Written English of Arab Palestinian Students (Unpublished MA thesis). Ball State University, Muncie: Indiana, USA.

Belhaj, A.M. (1997). Contrastive Textual Analysis: An Arabic-English, English-Arabic Translation Corpus: Occasional Papers, Vol. 24-25. 103 - 150.

Broselow, E. (1984). An Investigation of Transfer in Second Language Phonology. International Review of Applied Linguistics, 22, 253-269.

Broughton, G., Brumfit, C., Pincas, A., \& Wilde, R. D. (2002). Teaching English as a foreign language. Routledge.

Brown, G. and George, Y. (1933). Discourse Analysis. Cambridge: Cambridge University Press.

Brudhipr. Rafha, P. (1972). Error analysis: a psycholinguistic study of Thai English compositions. Thesis (Masters) McGill University: Australia.

Brown, D.B. (1994). Principles of Language Learning and Teaching (Third Edition). New Jersey: Prentice Hall Regents.

Candling, R. B. (2001). Vocabulary and language teaching. New York: Longman Inc.

Corder, S.P. (1967). The significance of learners' errors. London: Longman.

Corder, S.P. (1971). Idiosyncratic errors and Error Analysis. IRAL, 9(2), 147-159.

Corder, S.P. (1974). Error Analysis. In J.P.B. Allen and S. P. Corder (Ed.), Techniques in Applied Linguistics (The 
Edinburgh Course in Applied Linguistics), London: Oxford University Press

Corder, S.P. (1981). Error Analysis and Inter Language. Oxford: Oxford University Press.

Corder, S.P. (2000). Error Analysis. London: Longman Publishers.

Diab, N. (1996). The transfer of Arabic in the English writings of Lebanese students.

Retrieved from http://lael.pucsp.br/especialist/181diab. ps.pdf.

Dulay, H. \& Burt, M. (1974). You can’t learn without goofing. In J. C. Richards, Error analysis. (Ed.). London: Longman.

El-Sayed, A.M.M. (1982). An Investigation into the Syntactic Errors of Saudi Freshmen's English Compositions. Unpublished PhD. Dissertation. Pennsylvania U.S.A: Indiana University.

Ellis, R. (1996). The Study of Second Language Acquisition. Oxford: Oxford University Press.

Ellis, R. (1985). Understanding Second Language Acquisition. Oxford: Oxford University Press.

Ellis, R. (1997). SLA Research and Language Teaching. Oxford: Oxford University Press.

Farhat, S. H. (1994). Error Analysis: A Study of the Written Performance of University of Khartoum Freshmen (Unpublished MA Thesis in Applied Linguistics). Sudan: Khartoum University.

French, F.G. (1989). Common Errors in English. London: Oxford University Publishers.

Gass, S. M., and Selinker, L. (1994). Second language acquisition: An introductory course. Hillsdale, N. J: L. Erlbaum Associates.

Gass, S. and Selinker, L. (2001). Second Language Acquisition: an introductory course. Mahwah, NJ:LEA.

Habash, Z. (1982). Common Errors In The Use of English Prepositions In The Written Work Of UNRWA Students At The End Of The Preparatory Cycle In The Jerusalem Area. Retrieved from http://www.zeinab-habash.ws/education/books/master.pdf.

Jackson, H. (1981). Contrastive analysis as a predictor of errors, with reference to Punjabi learners of English. In Contrastive linguistics and the language teacher, J. Fisiak (ed.). Oxford: Pergamon.

Jain, M. (1974). Error Analysis: Source, Cause and Significance. In Richard, J. (ed.). Error analysis: Perspectives on Second Language Acquisition (pp. 189 - 250). Essex: Longman.

Johanson, S. (1975). The uses of Error Analysis and Contrastive Analysis I. English Language Teaching, 29(3), $246-253$

Kharma, N. (1981). Analysis of Errors Committed by Arab University Students in the Use of the English Definite Articles. IRAL, 4, 333-345.

Kharma, N. \& Hajjaj, H. (1989). Errors in English among Arabic Speakers: Analysis and Remedy. London: Longman Group UK Limited.

Krashen, S. (1982). Principles and practices in second language acquisition. Oxford: Pergamon Press.
Lado, R. (1957). Linguistics across Cultures. Ann Arbor: University of Michigan Press,

Lado, R. (1964). Language Teaching: A Scientific Approach. London: McGraw-Hill

Michaelides, N.N. (1990). Error Analysis: An Aid to Teaching. English Teaching Forum, 4, 28-30.

Olasehinde, M.O. (2000). Error Analysis and Remedial Pedagogy. In Babatunde S.T. and Adeyanju (Eds.), Language, Meaning and Society. Ilorin, Nigeria: Itaytee Press and Publishing Co.

Opara, S.C. (2001). Applied English Linguistics. Lagos: texcel Publishers.

Orisawayi, D. (1984). A Case for Integrating Language and Literature Components of English as a Second Language at Secondary School Level. Journal of English Studies, 1, 45-51.

Radwan, M.A. (1988). A Linguistic Analysis of the Grammatical and Lexical Errors in the Nominal Group Found in the Written English of Syrian University Students. Unpublished PhD. Dissertation. U.K: University of Nottingham.

Richards, J.C. (1974). Error Analysis. Perspectives on second language acquisition. London: Longman.

Richards, J.C. (1974). A Non-Contrastive Approach to Error Analysis. In Richards, J. (Ed.), Error analysis: Perspectives on Second Language Acquisition (pp. 172-188). Essex: Longman.

Richards, J.C. and Sampson, G. P. (1974). The study of learner English. In J.C. Richards (Ed.), Error Analysis. Perspectives on second language acquisition (pp. 3-18). Essex: Longman.

Richard, J. C. (1992). Dictionary of Language Teaching and Applied Linguistics ( $2^{\text {nd }}$ ed.). Essex: Longman Group UK Limited.

Schachter, J. (1974). An Error in Error Analysis. Language Learning 24(2), 205-214.

Scott, M. \& Tucker, R. (1974). Error analysis and English language strategies of Arab students. Language Learning, 24(2), 69-97.

Selinker, L. (1974). Inter-language. In Richards, J.C. (Ed.), Error analysis. Perspectives on Second Language Acquisition (pp. 31-54). Essex: Longman.

Selinker, L. (1992). Rediscovering Interlanguage. New York: Longman.

Stockell, R., Bowen, J., and Martin, J. (1965). The Grammatical Structure of English and Spanish. Chicago: University of Chicago Press.

Taylor, B.P. (1975). The use of overgeneralization and transfer learning strategies by elementary and intermediate students of ESL. Language Learning, 25, 73-107.

Wilcott, P. J. (1972). An Analysis of Written English of Native Speakers of Arabic as found in American History final Examination Given at the University of Texas at Austin. Unpublished PhD. Dissertation. Austin: The University of Texas.

Wilcott, PJ. (1978). Problems of Definitions in the Written English of Arabic Speakers. ELT Journal, 33 (1), 67-83.

Yankson, K. M. (2000). Better English though concord for West African Students. Uruowulu-Obosi: Pacific publishers. 